\title{
The Influence of COVID-19 Lockdown in Jordan on Patients with Diabetic Retinopathy: A Case-Control Study
}

\section{Rami Al-Dwairi (D) \\ Hamzeh Rwashdeh \\ Moneera Otoom}

Department of Special Surgery, Division of Ophthalmology, Faculty of Medicine, Jordan University of Science \&

Technology, Irbid, Jordan
Correspondence: Rami Al-Dwairi Department of Special Surgery, Division of Ophthalmology, Faculty of Medicine Jordan University of Science and

Technology, P. O. Box: 3030, Irbid, 221 I0, Jordan

Tel +962795355056

Fax +96227201064

Email ramialdwairi@yahoo.com
Background: Diabetic retinopathy (DR) is a leading cause of vision impairment in working-age adults. Patients with DR need extensive follow-ups with timely proper treatment. In Jordan, a complete lockdown was decided during the COVID-19 pandemic including the closure of outpatients' clinic. In this study, we assess the effect of the lockdown on the progression and visual outcome for patients with DR who had interruption in their plan.

Methods: Retrospectively, we identified all patients who were scheduled for procedures for the management of diabetic retinopathy (DR) during the COVID-19-related quarantine period in Jordan from March 16th to June 6th, 2020. All demographics and clinical data, procedure information, and visual outcome were collected. Another control group of patients with similar characteristics who were scheduled for procedures related to DR before the COVID-19 pandemic from October 15th to December 31st, 2019 were included.

Results: One hundred and thirty-seven eyes planned for procedures from 89 patients were included. The case group comprises 56 eyes $(40.9 \%)$. The mean age of the patients was 61.4 years. The right eye was involved in 69 procedures $(50.4 \%)$. The mean change in visual acuity for the case group in the procedure eye was 0.176 in LogMAR (drop of almost 9 $\operatorname{LogMAR}$ letters) and the mean change in visual acuity for the control group in the procedure eye was -0.103 LogMAR (gain of about 5 LogMAR letters). Also, the central subfield thickness (CST) values were significantly worse in the case group. Furthermore, patients in the case group had significantly more disease progression (new findings and worsening of the already established findings).

Conclusion: Interrupting the important procedures for DR patients and delaying their follow-up may adversely affect their visual outcome. National decisions should consider conducting these procedures and exempt those patients from any lockdown with proper precautions. Moreover, certain measures would be considered, such as treat-and-extend protocol, home screening and portable OCT examination, and newer long-acting antiVEGF drugs.

Keywords: diabetic retinopathy, COVID-19 lockdown, intravitreal injections, visual outcome, risk management

\section{Introduction}

At the end of December 2019, a cluster of cases of pneumonia was seen in Wuhan, a large city in China due to the Severe Acute Respiratory Syndrome Coronavirus 2 (SARS-CoV-2) virus. ${ }^{1}$ Subsequently, the World Health Organization (WHO) named it as the Coronavirus Disease 2019 (COVID-19) and one month later, COVID-19 was announced as a pandemic. ${ }^{2-4}$ In just a few months, the COVID-19 pandemic 
has reformed the modern world in unprecedented ways and disrupted health services worldwide. ${ }^{5-7}$ Due to the shortage of personal protective equipment (PPE) and ventilators, and in order to decrease the nosocomial transmission of COVID-19, and to maintain hospitals' capacity against the expanding numbers of COVID-19 patients, many hospitals had undergone temporary lockdown. ${ }^{8}$ These lockdown steps were established with inconsistent policies and little preparation. In addition, surgical residents were also diverted to COVID-19 teams to provide support in crisis situations. In Jordan, a complete quarantine and lockdown was declared from 16th of March to 6th of June in 2020 that involved cessation of public activities, stay-at-home orders, suspending all outpatient clinics, postponing all elective operations and closure of hospitals for all cases except for emergency cases. The number of patients encountered, and the number of medical procedures had dramatically decreased during the lockdown.

Diabetic retinopathy (DR) is a leading cause of vision impairment in working-age adults. ${ }^{9-11}$ The prevalence of retinopathy for all adults with diabetes in Jordan is $34.1 \%$, and worldwide, the prevalence of DR has been estimated at $22.27 \%{ }^{12,13}$ The prevalence of proliferative diabetic retinopathy (PDR) in one African country is estimated at $24.6 \% .{ }^{14}$ Many of these patients are candidates for intravitreal injection of anti-vascular endothelial growth factors (VEGF), photocoagulation laser, or surgical management according to the stage of DR and the treatment should be conducted promptly when indicated. ${ }^{15}$ During the period of lockdown in Jordan, ophthalmic outpatient visits were broadly reduced to urgent and emergent cases only, and the procedures along with operations were postponed. The aim of this case-control study is to evaluate the effect of the COVID-19 lockdown in Jordan on those diabetic patients whose procedures, appointments, and follow-up visits were delayed due to the complete national quarantine.

\section{Patients and Methods}

\section{Patients and Data}

This study was performed at King Abdullah University Hospital (KAUH), a tertiary care center located in North of Jordan, which is affiliated with the Jordan University of Science and Technology (JUST). After obtaining the Institutional Review Board (IRB), we retrospectively identified all patients who were scheduled for procedures for the management of diabetic retinopathy (DR) during the
COVID-19-related quarantine period in Jordan from March 16th to June 6th, 2020. Hospital electronic medical records were utilized to extract the following data including: demographics (age and sex), medical history (DM duration, $\mathrm{HbAlc}$, other comorbidities, past ocular history), procedure information (side of procedure (right versus left eye), type of procedure, indication of procedure), and the interrupting events related to the quarantine period. Also, clinical and visual baseline and outcomes (visual acuity, OCT findings, IOP measurement, new findings and worsening findings on examination) were retrieved. Another control group of patients with similar characteristics who were scheduled for procedures related to DR before the COVID-19 pandemic from October 15th to December 31st, 2019 was collected.

The study population was divided into case and control groups. The case group included patients who were planned for procedures for different indications, but the planned procedure was interrupted due to the lockdown. The lockdown in Jordan was a complete quarantine, which started from 16th of March 2020 to 6th of June 2020. During that period, almost all life aspects were upended including hospitals' services, such as outpatient clinic and elective operations. Any patient who was scheduled for other causes not related to DR, such as retinal vein occlusion, age-related macular degeneration or uveitis was excluded. In addition, patients who lost follow-up and did not have post-quarantine visits were excluded. The control group consisted of diabetic patients who were scheduled for procedures related to the management of DR complications within the period of 15 th of October to December 31st, 2019 where there were no restrictions of patients' movement and the COVID-19 pandemic had not reached Jordan yet.

The applied and scheduled procedures were intravitreal anti-VEGF injections (ranibizumab and aflibercept), retinal laser photocoagulation, and surgical interventions (pars plana vitrectomy). Indications for these procedures included vitreous hemorrhage $(\mathrm{VH})$, diabetic macular edema (DME), active proliferative diabetic retinopathy (PDR) (without $\mathrm{VH}$ ) and fibrovascular membranes (FVM) that required surgical removal. The interrupting events that resulted from the quarantine were categorized as either delay in the initiation of the treatment, incomplete treatment or completely missing the treatment. For the case group, dates of the last pre-quarantine visit, first post-quarantine visit, and original scheduling date of the procedure were reported. Also, the date of the performed 
procedure was documented, if given. Regarding the control group, dates of performed procedure, last pre-procedure visit, and first post-procedure visit were documented.

The outcomes were compared between both groups using different measures. First, the mean change in visual acuity was compared and studied. For the case group, the mean change in visual acuity between the last pre-quarantine visit and the first post-quarantine visit was calculated for both eyes (whether procedure eye or nonprocedure eye). Regarding the control group, the mean change of visual acuity was calculated from the last preprocedure visit and the first post-procedure visit for both eyes. Visual acuity was measured in decimal visual acuity and converted to the LogMAR visual acuity. For patients with a visual acuity of counting fingers, hand motion, light perception or "no light perception", they were converted according to the study of Schulze-Bonsel et al.$^{15}$

Furthermore, central subfield thickness (CST) on optical coherence tomography was obtained pre- and post-quarantine for the case group, and pre- and post-procedure for the control group. Moreover, intraocular pressure (IOP) was measured for both groups.

Clinical findings on ophthalmic examination were studied and compared between both groups for both procedure eye and non-procedure eye. They were divided into the development of new findings (such as the development of VH or FVM in eyes with active PDR) or worsening of already established findings (such as the worsening of FVM to apply traction on the retina or worsening of the neovascularization of retina (NVE's). Worsening of findings were measured and compared subjectively based on a bio-clinical examination by a single ophthalmologist for each patient. It was also measured objectively using OCT scans (such as traction caused by FVM). Any change in the management plan of the active disease was also documented and compared between both groups.

The DR changes were classified according to the 2019 American Academy of Ophthalmology "preferred practice pattern" guidelines. ${ }^{16}$

\section{Setting}

The decision on the procedures was based on the diagnoses and done by a single consultant vitreoretinal surgeon. Visual acuity was assessed using Snellen decimal projectors. IOP was measured by Goldmann tonometry, and anterior and posterior segment examination was performed through slit-lamp biomicroscope with the required non-contact hand-held lenses. The ophthalmic examination was done by well-trained residents and confirmed by the consultant vitreoretinal surgeon for suspicious cases. The OCT scans were obtained with the OCT device (TOPCON 3D OCT-2000, TOPCON medical systems, Inc., Oakland, $\mathrm{NJ}$ ) by a well-trained optician.

Injections were administered using expert committee guidelines in accordance with the international guidelines, including the use of topical $5 \%$ povidone iodine at the injection site and the use of eyelid speculum to avoid eyelid contact with the needle. Pan-retinal photocoagulation (PRP) laser treatment was given after fully dilating the pupil through a double frequency yttrium-aluminum-garnet (YAG) laser. Injections and lasers were done according to similar guidelines by well-trained senior residents. The surgical operations were performed by a consultant vitreoretinal surgeon and comprised a pars plana vitrectomy approach for the removal of FVM and repair of tractional retinal detachment or for organized $\mathrm{VH}$.

\section{Statistical Analysis}

Extracted data were entered into a spreadsheet. Statistical analysis was performed using the IBM SPSS statistical package for Windows v.22 (Armonk, New York, USA). Data were expressed as frequency (percentage) for nominal data, mean \pm standard deviation of the mean (SD) for normally distributed continuous variables. Normality was tested using Kolmogorov-Smirnov test. Statistical significance between the study groups regarding the previously mentioned parameters was determined using Chi-square test for categorical variables, and Student's $t$-test and ANOVA test for continuous variables. $P \leq 0.05$ was considered statistically significant. A simple linear regression test was applied to study the relation between two continuous variables. Multiple logistic regression analyses were performed to study the multiple effects of different variables. The sample size was confirmed retrospectively at the alpha level of 0.05 and the power of analysis at $90 \%$ and found to be at least 56 for each group.

\section{Results}

\section{Demographics and Patients' Characteristics}

One hundred and thirty-seven eyes planned for procedures from 89 patients were included in the study. The case group comprises 56 eyes $(40.9 \%)$. The mean age of the patients was 61.4 years, and 48 of the patients were females $(53.9 \%)$. The mean duration of DM was 18.3 
years with a mean $\mathrm{HbAlc}$ percent of $8.62 \%$ and 74 (83.1\%) of the patients have other comorbidities (mainly hypertension, ischemic heart disease and dyslipidemia). The right eye was involved in 69 procedures $(50.4 \%)$.

Regarding the procedures, $123(89.8 \%)$ eyes were scheduled for or given injections and/or laser, while 14 (10.2\%) were planned for surgery. DME was the most common indication for the procedures in $76(55.5 \%)$, followed by active PDR without $\mathrm{VH}$ in $30(21.9 \%)$, VH in $18(13.1 \%)$ and FVM requiring surgery in $13(9.5 \%)$.

All patients in the control group did not have interrupting events which was consistent with the definition of the control group and the period of involvement. Regarding the case group, 17 had delay in the initiation of treatment, 30 had incomplete treatment, and 9 did not take any treatment during the duration of lockdown.

The mean visual acuity for the procedure eye and the non-procedure eye with the mean change in the visual acuity are summarized in Table 1.

Also, the mean CST on OCT pre- and post-intervals are also summarized in Table 1 along with the measurement of IOP.

The new findings in the procedure eye developed in 23 (16.9\%) eyes and included: $\mathrm{VH}$, rubeosis, FVM, and signs of PDR. Also, 28 (20.6\%) had worsening of the already established findings. Regarding the non-procedure eye, 19 (14\%) developed new findings and 21 (15.4\%) had worsening of the findings. The plan of treatment was changed in $13(9.5 \%)$ patients.

\section{Case versus Control (The Effect of COVID-19 Lockdown)}

There was no statistical difference between the case and control groups regarding the sex, age, DM duration, $\mathrm{HbAlc} \mathrm{level,} \mathrm{and} \mathrm{side} \mathrm{of} \mathrm{procedure} \mathrm{(laterality).} \mathrm{Also,} \mathrm{the}$ frequency of different types of interventions was similar in both groups. Furthermore, there was no difference in the indications between both groups. Table 2 summarizes the differences between case and control groups.

Regarding the visual outcome, the mean visual acuity at the time of plan was similar in both groups. However, the control group had better visual acuity in the postintervention visits than the case group. Accordingly, the mean change in visual acuity for the case group in the procedure eye was 0.176 in LogMAR, which signifies a prominent drop in vision of almost 9 LogMAR letters. On the other hand, the mean change in visual acuity for the control group in the procedure eye was -0.103 LogMAR, which corresponds to a gain of about 5 LogMAR letters. The difference between the two groups was 14 LogMAR letters. The mean change in visual acuity was also found to be significantly different between case and control in all indications' subgroups.

Although it was not statistically significant, the difference between the drop in visual acuity for the case group and the gain in visual acuity for the control group in the non-procedure eye corresponded to 7 LogMAR letters.

Regarding the CST values, it was found that the case group had a statistically significant worsening of CST values compared to the control group ( $\mathrm{P}=0.025)$. The IOP measurements were similar between both groups post-visits.

More importantly, patients in the case group had significantly more disease progression (new findings and worsening of the established findings) in both the procedure eye and the non-procedure eye, which indicates the significant negative impact of the lockdown on those patients.

\section{Factors Affecting the Mean Change in Visual Acuity}

As aforementioned, the case group had a greater reduction in visual acuity than the control group (a difference of 14 LogMAR letters $)(P=0.003)$. Also, it was found that patients with $\mathrm{VH}$ had an improvement in visual acuity compared to other indications $(\mathrm{P}=0.04)$. Patients who completely missed their procedure had the worst deterioration in visual acuity $(P=0.001)$. In addition, it was found that the patients' age negatively correlated with visual acuity where getting older by 5 years was associated with a reduction of vision by 3 LogMAR letters. Other factors such as gender, DM duration and HbAlc were not associated with a significant change in visual acuity Table 3.

After performing multiple linear regression analysis, it was found that the two independent factors affecting visual acuity belonged to the case group and increased in age.

\section{Factors Affecting the Progression of Disease (New Findings and Worsening of the Established Findings) in the Procedure Eye}

Similar to the visual acuity, the case group had significantly more new and/or worsening of findings in the procedure eye $(\mathrm{P}=0.0001)$. Also, patients with no interrupting events had much less disease progression. 
Table I General Demographical Characteristics of Both Case and Control Groups

\begin{tabular}{|c|c|c|}
\hline \multirow[t]{2}{*}{ Variables } & Number & $\begin{array}{l}\text { Percentage } \\
\text { (\%) }\end{array}$ \\
\hline & \multicolumn{2}{|c|}{ Mean \pm SEM } \\
\hline \multicolumn{3}{|l|}{ Case versus Control } \\
\hline Case & 56 & 40.9 \\
\hline Control & 81 & 59.1 \\
\hline \multicolumn{3}{|l|}{ Gender } \\
\hline Male & 41 & 46.1 \\
\hline Female & 48 & 53.9 \\
\hline Age (years) & \multicolumn{2}{|c|}{$61.4 \pm 0.9$} \\
\hline DM duration (years) & \multicolumn{2}{|c|}{$18.3 \pm 0.7$} \\
\hline HBAIC (\%) & \multicolumn{2}{|c|}{$8.62 \pm 0.2$} \\
\hline Other co-morbidities & 74 & 83.1 \\
\hline \multicolumn{3}{|l|}{ Side of procedure (laterality) } \\
\hline Right (OD) & 69 & 50.4 \\
\hline Left (OS) & 68 & 49.6 \\
\hline \multicolumn{3}{|l|}{ Type of procedure } \\
\hline Injection and/or laser & 123 & 89.8 \\
\hline Surgery & 14 & 10.2 \\
\hline \multicolumn{3}{|l|}{ Indication } \\
\hline $\mathrm{VH}$ & 18 & 13.1 \\
\hline DME & 76 & 55.5 \\
\hline Active PDR without VH & 30 & 21.9 \\
\hline FVM requiring surgery & 13 & 9.5 \\
\hline \multicolumn{3}{|l|}{ Interrupting event } \\
\hline No & 81 & 59.1 \\
\hline Delay initiation of treatment & 17 & 12.4 \\
\hline Incomplete treatment & 30 & 21.9 \\
\hline Missed treatment & 9 & 6.6 \\
\hline $\begin{array}{l}\text { Interval between last visit pre- } \\
\text { quarantine and Ist visit post- } \\
\text { quarantine for case group (days) }\end{array}$ & \multicolumn{2}{|c|}{$169.2 \pm 8.7$} \\
\hline \multicolumn{3}{|l|}{ Overall visual outcome } \\
\hline $\begin{array}{l}\text { Pre VA for the procedure eye } \\
\text { (LogMAR) }\end{array}$ & \multicolumn{2}{|c|}{$0.838 \pm 0.06$} \\
\hline $\begin{array}{l}\text { Post VA for the procedure eye } \\
\text { (LogMAR) }\end{array}$ & \multicolumn{2}{|c|}{$0.846 \pm 0.05$} \\
\hline $\begin{array}{l}\text { Change in VA for the procedure eye } \\
\text { (LogMAR) }\end{array}$ & \multicolumn{2}{|c|}{$0.007 \pm 0.05$} \\
\hline $\begin{array}{l}\text { Pre VA for the non-procedure eye } \\
\text { (LogMAR) }\end{array}$ & \multicolumn{2}{|c|}{$0.889 \pm 0.06$} \\
\hline $\begin{array}{l}\text { Post VA for the non-procedure eye } \\
\text { (LogMAR) }\end{array}$ & \multicolumn{2}{|c|}{$0.923 \pm 0.06$} \\
\hline
\end{tabular}

(Continued)
Table I (Continued).

\begin{tabular}{|c|c|c|}
\hline \multirow[t]{2}{*}{ Variables } & Number & $\begin{array}{c}\text { Percentage } \\
\text { (\%) }\end{array}$ \\
\hline & \multicolumn{2}{|c|}{ Mean \pm SEM } \\
\hline $\begin{array}{l}\text { Change in VA for the non-procedure } \\
\text { eye (LogMAR) }\end{array}$ & \multicolumn{2}{|c|}{$0.0291 \pm 0.04$} \\
\hline Overall OCT outcome & \\
\hline Pre CST (micron) & \multicolumn{2}{|c|}{$340.8 \pm 14.2$} \\
\hline Post CST (micron) & \multicolumn{2}{|c|}{$320 . \pm 10.9$} \\
\hline Change in CST (micron) & \multicolumn{2}{|c|}{$-28.0 \pm 6.3$} \\
\hline Overall IOP outcome & \\
\hline Pre IOP for OD $(\mathrm{mmHg})$ & \multicolumn{2}{|c|}{$15.46 \pm 0.3$} \\
\hline Post IOP for OD (mmHg) & \multicolumn{2}{|c|}{$15.44 \pm 0.2$} \\
\hline Pre IOP for OS $(\mathrm{mmHg})$ & \multicolumn{2}{|c|}{$16.02 \pm 0.4$} \\
\hline Post IOP for OS (mmHg) & \multicolumn{2}{|c|}{$16.25 \pm 0.5$} \\
\hline New findings in the procedure eye & 23 & 16.9 \\
\hline $\begin{array}{l}\text { Worsening findings in the } \\
\text { procedure eye }\end{array}$ & 28 & 20.6 \\
\hline $\begin{array}{l}\text { New findings in the non-procedure } \\
\text { eye }\end{array}$ & 19 & 14.0 \\
\hline $\begin{array}{l}\text { Worsening findings in the non- } \\
\text { procedure eye }\end{array}$ & 21 & 15.4 \\
\hline Change in plan & 13 & 9.5 \\
\hline
\end{tabular}

Abbreviations: SEM, standard error of the mean; DM, diabetes mellitus; OD, right eye; OS, left eye; VH, vitreous hemorrhage; DME, diabetic macular edema; PDR, proliferative diabetic retinopathy; FVM, fibrovascular membrane; VA, visual acuity; OCT, optical coherence tomography; CST, central subfield thickness; IOP, intraocular pressure.

Moreover, females had more worsening findings than males $(\mathrm{P}=0.033)$. Furthermore, patients who were planned for surgery or performed surgical intervention had significantly more worsening of the established findings than patients with injection and/or laser $(\mathrm{P}=0.009)$. In addition, patients who were treated for active PDR (without $\mathrm{VH}$ ) and $\mathrm{FVM}$ had more worsening findings than patients treated for DME and VH $(\mathrm{P}=0.001)$. Table 4 summarizes the factors affecting the new and worsening findings of the same eye of procedure.

After performing a binary logistic regression analysis, it was found that belonging to the case group (patients who missed the planned procedure due to COVID-19 lockdown) was the most significant and the only independent factor affecting the development of the new findings. Patients in the case group were 21.9-fold more likely to develop new findings. Regarding 
Table 2 Comparison Between Case Group (Patients Who Had Interrupting Events Because of COVID-I9 Quarantine and Control Group)

\begin{tabular}{|c|c|c|c|}
\hline Variables & Case (\%) & Control (\%) & $P$-value \\
\hline \multicolumn{4}{|l|}{ Gender } \\
\hline Male & $24(42.9)$ & $39(48.1)$ & NS \\
\hline Female & $32(57.1)$ & $42(51.9)$ & \\
\hline Age; Mean \pm SEM (years)* & $60.3 \pm 1.3$ & $62.1 \pm 1.2$ & NS \\
\hline DM duration; Mean \pm SEM (years)* & $17.1 \pm 1.0$ & $18.9 \pm 1.0$ & NS \\
\hline HBAIC; Mean \pm SEM (\%)* & $8.9 \pm 0.2$ & $8.5 \pm 0.2$ & NS \\
\hline Other co-morbidities & $51(91.1)$ & $58(71.6)$ & 0.004 \\
\hline \multicolumn{4}{|l|}{ Side of procedure (laterality) } \\
\hline Right (OD) & $28(50)$ & $4 \mathrm{I}(50.6)$ & NS \\
\hline Left (OS) & $28(50)$ & $40(49.4)$ & \\
\hline \multicolumn{4}{|l|}{ Type of procedure } \\
\hline Injection and/or laser & $47(83.9)$ & $76(93.8)$ & NS \\
\hline Surgery & $9(16.1)$ & $5(6.2)$ & \\
\hline \multicolumn{4}{|l|}{ Indications } \\
\hline $\mathrm{VH}$ & $10(17.9)$ & $8(9.9)$ & \\
\hline DME & $27(48.2)$ & $49(60.5)$ & NS \\
\hline Active PDR without VH & II (19.6) & $19(23.5)$ & \\
\hline FVM requiring surgery & $8(14.3)$ & $5(6.2)$ & \\
\hline \multicolumn{4}{|l|}{ Interrupting event } \\
\hline No & $0(0)$ & $81(100)$ & \\
\hline Delay initiation of treatment & $17(30.4)$ & $0(0)$ & \\
\hline Incomplete treatment & $30(53.6)$ & $0(0)$ & 0.000 \\
\hline Missed treatment & $9(16.1)$ & $0(0)$ & \\
\hline \multicolumn{4}{|l|}{ Visual outcome; Mean \pm SEM* } \\
\hline Pre VA for the procedure eye (LogMAR) & $0.868 \pm 0.09$ & $0.819 \pm 0.08$ & NS \\
\hline Post VA for the procedure eye (LogMAR) & $1.058 \pm 0.09$ & $0.710 \pm 0.06$ & 0.001 \\
\hline Change in VA for the procedure eye (LogMAR) & $0.176 \pm 0.07$ & $-0.103 \pm 0.06$ & 0.003 \\
\hline Pre VA for the non-procedure eye (LogMAR) & $0.883 \pm 0.09$ & $0.893 \pm 0.08$ & NS \\
\hline Post VA for the non-procedure eye (LogMAR) & $1.016 \pm 0.09$ & $0.864 \pm 0.08$ & NS \\
\hline Change in VA for the non-procedure eye (LogMAR) & $0.117 \pm 0.06$ & $-0.026 \pm 0.04$ & NS \\
\hline \multicolumn{4}{|l|}{ OCT outcome; Mean \pm SEM* } \\
\hline Pre CST (micron) & $337.3 \pm 23.5$ & $343.1 \pm 17.8$ & NS \\
\hline Post CST (micron) & $351.0 \pm 19.5$ & $301.9 \pm 12.6$ & 0.029 \\
\hline Change in CST (micron) & $46.3 \pm 14.6$ & $-17.0 \pm 4.8$ & 0.025 \\
\hline New findings in the procedure eye & $18(32.7)$ & $5(6.2)$ & 0.0001 \\
\hline Worsening findings in the procedure eye & $24(43.6)$ & $4(4.9)$ & 0.0001 \\
\hline New findings in the non-procedure eye & $15(27.3)$ & $4(4.9)$ & 0.0001 \\
\hline Worsening findings in the non-procedure eye & $16(29.1)$ & $5(6.2)$ & 0.0001 \\
\hline Change in plan & $13(23.2)$ & $0(0)$ & 0.0001 \\
\hline
\end{tabular}

Note: *All tests used in this table are chi-square except for those with $\left(^{*}\right) t$-test was applied.

Abbreviations: SEM, standard error of the mean; DM, diabetes mellitus; OD, right eye; OS, left eye; VH, vitreous hemorrhage; DME, diabetic macular edema; PDR, proliferative diabetic retinopathy; FVM, fibrovascular membrane; VA, visual acuity; OCT, optical coherence tomography; CST, central subfield thickness; IOP, intraocular pressure; NS, not significant. 
Table 3 Factors Influencing the Change in Visual Acuity for the Same Eye of Procedure for Both Case and Control

\begin{tabular}{|c|c|c|}
\hline Factors & $\begin{array}{l}\text { Change in VA of the Same Eye of Procedure (LogMAR) } \\
\text { (Mean } \pm \text { SEM) (B Value for Interval Variable } \pm \text { SEM) }\end{array}$ & $P$ value \\
\hline $\begin{array}{l}\text { Case versus control } \\
\text { Case } \\
\text { Control }\end{array}$ & $\begin{array}{l}0.176 \pm 0.07 \\
-0.103 \pm 0.06\end{array}$ & 0.003 \\
\hline $\begin{array}{l}\text { Gender } \\
\text { Male } \\
\text { Female }\end{array}$ & $\begin{array}{l}-0.101 \pm 0.09 \\
0.085 \pm 0.04\end{array}$ & NS \\
\hline $\begin{array}{l}\text { Side of procedure (laterality) } \\
\text { Right (OD) } \\
\text { Left (OS) }\end{array}$ & $\begin{array}{l}-0.053 \pm 0.07 \\
0.069 \pm 0.06\end{array}$ & NS \\
\hline $\begin{array}{l}\text { Type of procedure } \\
\text { Injection and/or laser } \\
\text { Surgery }\end{array}$ & $\begin{array}{l}0.0076 \pm 0.04 \\
0.0021 \pm 0.3\end{array}$ & NS \\
\hline $\begin{array}{l}\text { Indication } \\
\text { VH } \\
\text { DME } \\
\text { FVM requiring surgery } \\
\text { Active PDR }\end{array}$ & $\begin{array}{l}-0.376 \pm 0.3 \uparrow \\
0.0579 \pm 0.03 \\
0.2719 \pm 0.2 \\
-0.0342 \pm 0.07\end{array}$ & 0.04 \\
\hline $\begin{array}{l}\text { Interrupting event } \\
\text { No } \\
\text { Delay initiation } \\
\text { Incomplete treatment } \\
\text { Missed treatment }\end{array}$ & $\begin{array}{l}-0.103 \pm 0.06 \uparrow \uparrow \\
0.129 \pm 0.2 \\
0.038 \pm 0.09 \\
0.438 \pm 0.07\end{array}$ & 0.001 \\
\hline Age (B value \pm SEM); (years) & $0.012 \pm 0.004$ & 0.008 \\
\hline DM duration (B value \pm SEM); (years)* & $-0.007 \pm 0.006$ & NS \\
\hline HBAIC (B value \pm SEM); (\%)* & $-0.005 \pm 0.02$ & NS \\
\hline $\begin{array}{l}\text { Interval between last visit pre- quarantine and Ist visit } \\
\text { post-quarantine for case group (B value } \pm \text { SEM); (days)* }\end{array}$ & $-0.002 \pm 0.001$ & NS \\
\hline
\end{tabular}

Note: *All tests used in this table are $t$-test or ANOVA test except for those with $\left(^{*}\right)$ simple regression test was applied. $\uparrow$ and $\uparrow \uparrow$, significant increase.

Abbreviations: SEM, standard error of the mean; DM, diabetes mellitus; OD, right eye; OS, left eye; VH, vitreous hemorrhage; DME, diabetic macular edema; PDR, proliferative diabetic retinopathy; FVM, fibrovascular membrane; NS, not significant.

worsening of the already established findings, belonging to the case group and/or to the active PDR (without VH) subgroup as an indication were the two independent factors. Patients in the case group were at 21.1-fold increased chance of worsening their findings. Also, patients with active PDR (without $\mathrm{VH}$ ) were at 4.8-fold increased chance of developing worsening findings.

A sub-analysis was done to compare the development of new and worsening findings between case and control within indication categories, which also illustrated the significant difference between both groups. Figures 1 and 2 summarize these results.

\section{Discussion}

This study highlights the influence of COVID-19 lockdown on those patients who were planned for intravitreal injections, laser, or surgical intervention due to DR complications. Our results indicated a difference in visual acuity of 14 LogMAR letters in patients belonging to the case group compared to the control group who achieved their planned treatment at the proper time. Also, the results revealed the significant increased number of disease progression in the form of new findings and/or worsening of the already established findings in the case group for both the procedure eye and the non-procedure eye. Furthermore, the results showed that patients with active 
Table 4 Factors Affecting the Occurrence of Both New Findings and Worsening Findings in the Procedure Eye

\begin{tabular}{|c|c|c|c|c|}
\hline Variables & $\begin{array}{l}\text { New } \\
\text { Findings } \\
\text { (\%) }\end{array}$ & $P$-value & $\begin{array}{l}\text { Worsening } \\
\text { Findings (\%) }\end{array}$ & $P$-value \\
\hline \multicolumn{5}{|l|}{ Case versus control } \\
\hline Case & $18(32.7)$ & 0.0001 & $24(43.6)$ & 0.0001 \\
\hline Control & $5(6.2)$ & & $4(4.9)$ & \\
\hline \multicolumn{5}{|l|}{ Gender } \\
\hline Male & $13(2 \mid .0)$ & NS & $8(12.9)$ & 0.033 \\
\hline Female & $10(13.5)$ & & $20(27.0) \uparrow$ & \\
\hline DM duration; Mean \pm SEM (years)* & $16.7 \pm 1.6$ & NS & $17.4 \pm 1.8$ & NS \\
\hline HBAIC; Mean \pm SEM (\%)* & $9.1 \pm 0.4$ & NS & $8.7 \pm 0.4$ & NS \\
\hline \multicolumn{5}{|l|}{ Side of procedure (laterality) } \\
\hline Right (OD) & II (I6.2) & NS & $17(25.0)$ & NS \\
\hline Left (OS) & $12(17.6)$ & & II (I6.2) & \\
\hline \multicolumn{5}{|l|}{ Type of procedure } \\
\hline Injection and/or laser & $20(16.4)$ & NS & $21(17.2)$ & 0.009 \\
\hline Surgery & $3(21.4)$ & & $7(50.0) \uparrow$ & \\
\hline \multicolumn{5}{|l|}{ Indication } \\
\hline $\mathrm{VH}$ & $4(22.2)$ & & $4(22.2)$ & \\
\hline DME & $9(12.0)$ & NS & $7(9.3) \downarrow$ & 0.001 \\
\hline Active PDR & $8(26.7)$ & & II (36.7) $\uparrow$ & \\
\hline FVM requiring surgery & $2(15.4)$ & & $6(46.2) \uparrow \uparrow$ & \\
\hline \multicolumn{5}{|l|}{ Interrupting event } \\
\hline No & $5(6.2) \downarrow$ & & $4(4.9) \downarrow$ & \\
\hline Delay initiation of treatment & $6(35.3)$ & 0.001 & $7(4 \mid .2)$ & \\
\hline Incomplete treatment & $9(31.0)$ & & II (37.9) $\uparrow$ & 0.0001 \\
\hline Missed treatment & $3(33.3)$ & & $6(66.7) \uparrow$ & \\
\hline $\begin{array}{l}\text { Interval between last visit pre- quarantine and Ist visit post-quarantine for } \\
\text { case group; Mean } \pm \text { SEM (days)* }\end{array}$ & $162.8 \pm 8.7$ & NS & $184.9 \pm 12.8$ & NS \\
\hline
\end{tabular}

Note: *All tests used in this table are chi-square except for those with $(*) t$-test was applied. $\uparrow$ and $\uparrow \uparrow$, significant increase; $\downarrow$, significant reduction.

Abbreviations: SEM, standard error of the mean; DM, diabetes mellitus; OD, right eye; OS, left eye; VH, vitreous hemorrhage; DME, diabetic macular edema; PDR, proliferative diabetic retinopathy; FVM, fibrovascular membrane; NS, not significant.

features of PDR and/or with proliferation of FVM were more prone to worsening of their findings if they did not receive the planned treatment. Moreover, elderly patients were at a higher chance for visual acuity deterioration. Ashkenazy et al studied the short-term effect of deferral of intravitreal injection visits due to COVID-19 pandemic. ${ }^{17}$ They found that patients with delayed visits had a greater decline in visual acuity of 3 letters and higher rates of worsening OCT results. ${ }^{17}$ In their study about the delay of intravitreal injection, Elfalah et al concluded that delay of more than 2 months and the previous need for 3 or more injections were significant poor prognostic factors for visual outcome for patients with DME. ${ }^{18}$
Another important issue is the negative impact of delaying the treatment of diabetic patients for their diabetes and comorbidities.

DR progresses in an orderly pattern from mild to more severe stages when there is no appropriate intervention. It is important to recognize the stages when treatment may be most beneficial. When the diagnosis is made correctly and the treatment is directed promptly, the rate of prevention of the occurrence of severe vision loss may reach up to $90 \% .{ }^{19}$ Multiple studies have demonstrated the benefit of anti-VEGF injections in the case of DME. ${ }^{20-22}$ The Diabetic Retinopathy Study studied the use of photocoagulation laser in reducing visual loss in PDR and it was 


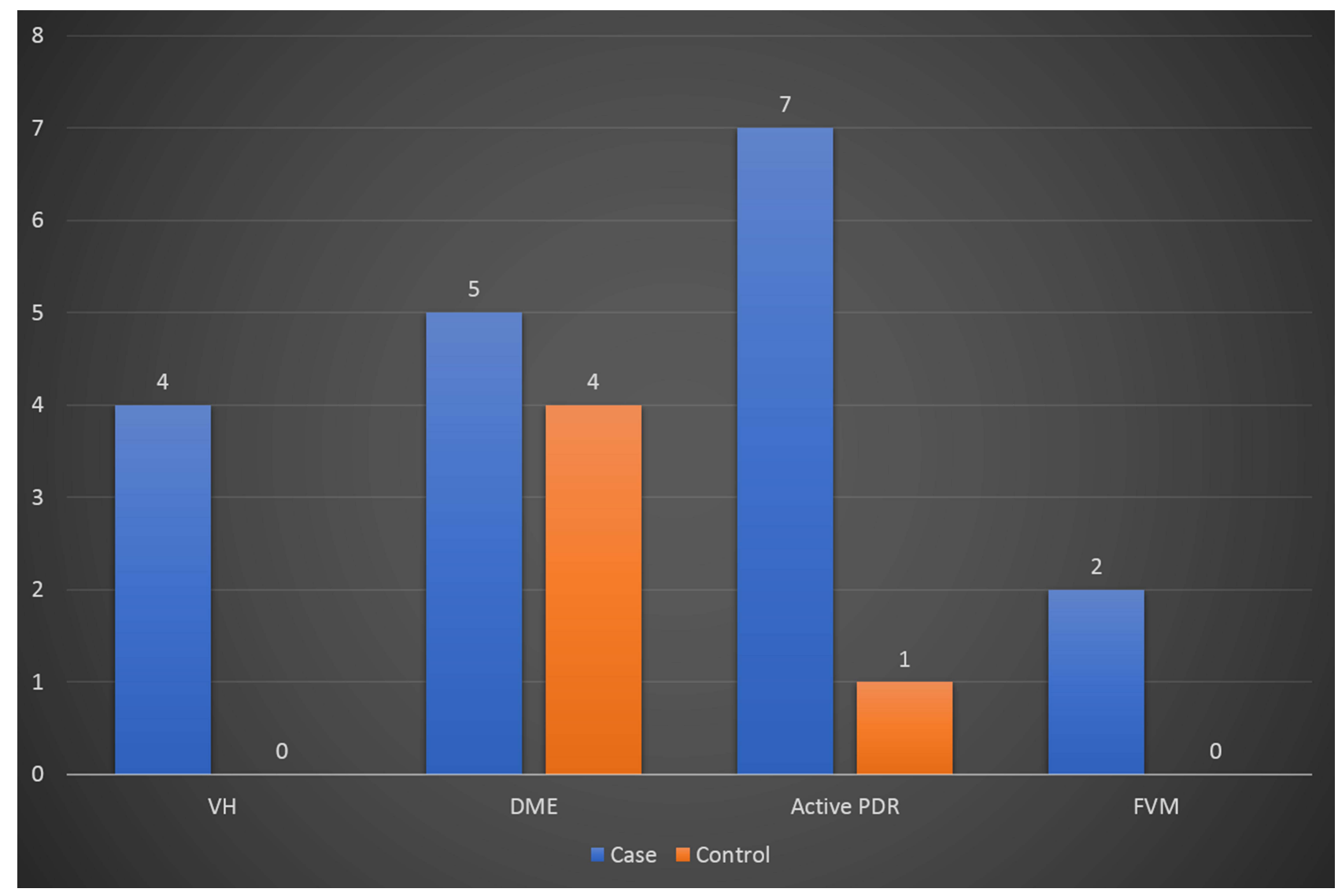

Figure I Comparing numbers of new findings between case and control groups within the indications ( $Y$ axis represents number of cases).

found that PRP reduced visual loss by $50 \%$ compared to no treatment. ${ }^{23}$ PRP aims to destroy non-perfused parts of the retina by reducing ischemia and intravitreal VEGFlevels. ${ }^{24}$ Regarding the role of surgery, The Diabetic Retinopathy Vitrectomy Study (DRVS) evaluated early vitrectomy for severe active FVM and they found that the final visual acuity of $20 / 40$ or better at 4 years follow-up was achieved by $44 \%$ of the early vitrectomy group and $28 \%$ of the conventional management group. ${ }^{25}$ Also, persistent or recurrent $\mathrm{VH}$ remains a common indication for surgery. ${ }^{25}$ TRD with recent macular involvement is a well-established indication for vitrectomy surgery, although the visual outcome may be variable due to irreversible macular dysfunction. ${ }^{26-28}$ However, missing follow-up carries higher risk of losing vision to macular involvement due to progression of TRD. It is worth mentioning that most cases of $\mathrm{VH}$ may be resolved spontaneously without treatment. ${ }^{29}$

Regardless of the national lockdown in Jordan that ceased most activities and transportations, ophthalmologists are still at a high risk of COVID-19 transmission given the close contact during examination. Also, some debatable studies demonstrated the virus material within ocular tissues and fluids. $\mathrm{Lu}$ et al reported that ocular surfaces may be a potential target for SARS-CoV-2 invasion. ${ }^{30}$ Qing et al showed that some COVID-19 patients complained of conjunctivitis, but not all of them tested positive for SARS-CoV-2 nucleic acid in conjunctival sac swabs. ${ }^{31}$ On the other hand, there were some patients who did not have conjunctivitis but tested positive for the SARS-CoV-2 nucleic acid in their conjunctival sac swabs. ${ }^{31} \mathrm{Xia}$ et al reported that only one patient's samples (two samples) of tear were positive for SARS-CoV-2. ${ }^{2}$ Moreover, Seah et al suggested a low risk of ocular transmission for SARS-CoV-2. ${ }^{32}$ During their study, 64 tear samples from a total of 17 COVID-19 patients were collected between the third and twentieth days following the initial symptoms. ${ }^{32}$ They found that neither viral culture nor polymerase chain reaction (PCR) detected the virus. ${ }^{32}$ Furthermore, Wu et al revealed that two patients with COVID-19 had positive conjunctival PCR out of 28 patients. Conversely, several studies have demonstrated that it is still transmissible through the tear film and through aerosol contact with the conjunctiva. ${ }^{34-36}$ Furthermore, the virus can survive and 


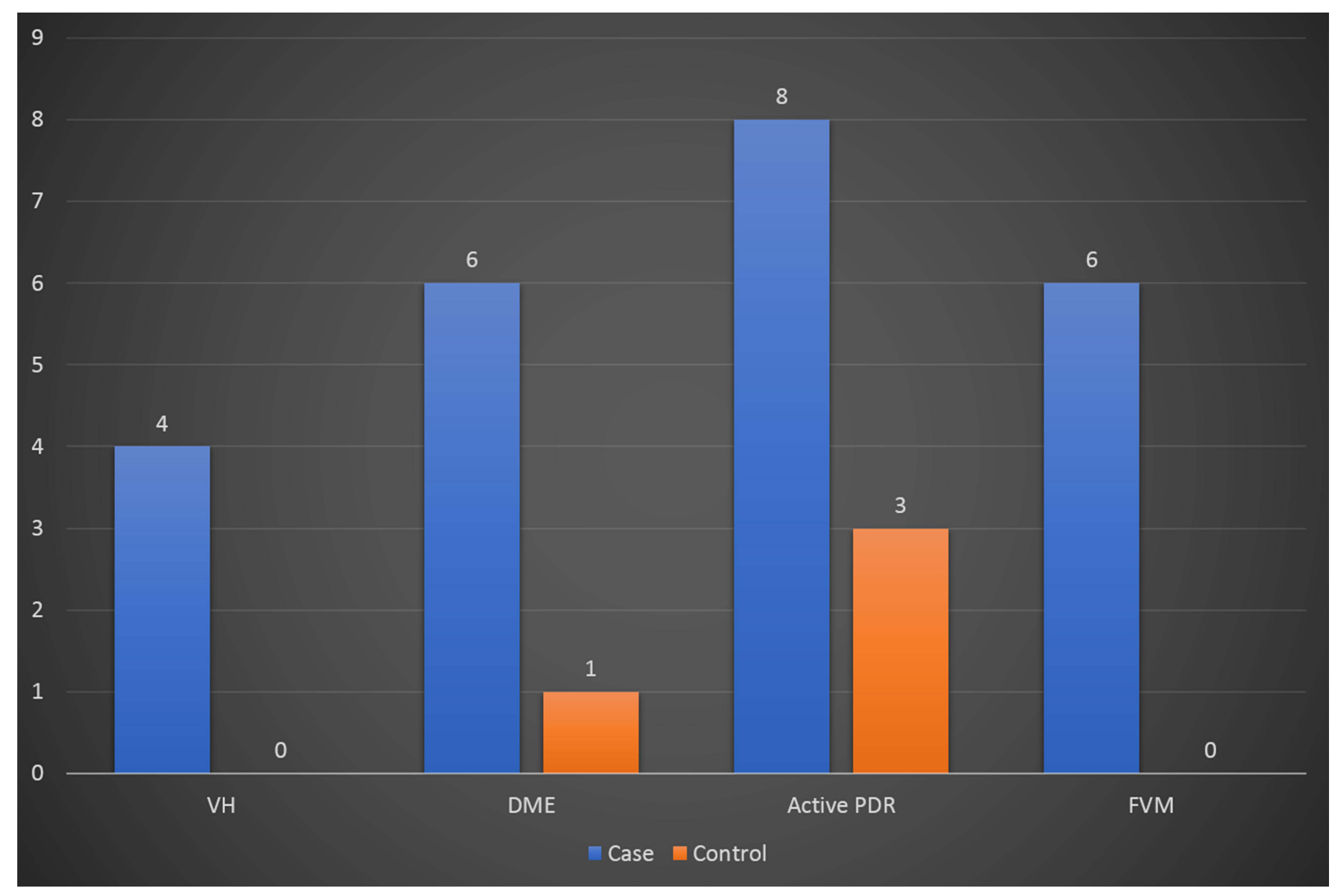

Figure 2 Comparing numbers of worsening findings between case and control groups within the indications ( $Y$ axis represents number of cases).

replicate in the conjunctiva even when no signs of conjunctivitis are visible. ${ }^{36}$ In addition, Casagrande et al found SARS-CoV-2 genetic material in the retina of COVID-19 patients. $^{37}$

During the early period of COVID-19 pandemic, the American Academy of Ophthalmology (AAO) published a recommended practice guideline urging practicing ophthalmologists to provide care for only "urgent" or "emergent" cases. ${ }^{38}$ The Academy recognized that "urgency" is determined by physician's own judgment. While the AAO recommendation left the decision of determining urgency or emergency to the treating physicians, the American Society of Retina Specialists described intravitreal injection therapy as "essential". ${ }^{39}$ Results from our work demonstrate the severe negative impact of delaying such important procedures for patients with diabetes. The sense of sight plays a fundamental role in our lives, which when compromised might negatively affect the quality of life of individuals. Similar to prioritizing treatment to cancer patients during total lockdowns, patients who need procedures for different retinal diseases should be prioritized with all ethical consideration given that full precautions that would prevent the transmission of COVID-19 infection are taken.

Limitations to our study include the retrospective nature of our study. This study also evaluated the short-term effect of delaying such procedures in patients with DR, and it did not evaluate the long-term effect of delaying the procedures or the effect of resuming the treatment. Moreover, this study included only patients with DR and its complication, many other important retinal diseases such as retinal vein occlusion and age-related macular degeneration would probably behave in a similar manner. Another point is that some laboratory parameters, such as the variation of the level of $\mathrm{HbAlc}$ that may affect the outcome, were not provided due to the retrospective nature of the study, the improper documentation of multi-center investigation and the delay in doing these tests in the lockdown period.

\section{Conclusions}

DR is the leading cause of blindness in the working age group. Delaying the important procedures for such patients would adversely affect their visual outcome. Healthcare policy makers should consider conducting these 
procedures and exempt those patients from any lockdown with proper precautions. One option is to send an email explaining the emergency need for the intervention and allow patients to show it to all the concerned authorities on the way to the hospital. Also, we recommend that ophthalmologists consider switching their patients who are planned for injections from pro re nata (PRN) approach to the treat-and-extend protocol where the patients are kept on continuous therapy without the need for regular and extensive outpatient visits. In addition, ophthalmologists may plan their patients for additional injections to overcome the possibility of any lockdown and outpatient's clinic closure. Moreover, home screening and portable OCT examination could be considered as a possible solution. Furthermore, larger studies, protocols and trials should be conducted to evaluate the efficacy of using newer long-acting anti-VEGF drugs in such circumstances.

\section{Availability Data and Materials}

The datasets generated and analyzed during the current study are available from the corresponding authors.

\section{Ethical Approval}

This study was performed in accordance with the ethical standards laid down in the 1964 Declaration of Helsinki and its later amendment. This research has obtained ethical approval from the Research and Ethics Committee, at Jordan University of Science and Technology and King Abdullah University Hospital, Irbid, Jordan. We confirm that the privacy of the participants was saved, and the data was anonymized and maintained with confidentiality. The need for consent was waived by our institutional review board due to the retrospective nature of the study.

\section{Funding}

The authors have not declared any grant for this work from any funding authority.

\section{Disclosure}

The authors have no conflicts of interest to disclose.

\section{References}

1. Zhu N, Zhang D, Wang W, et al. A novel coronavirus from patients with pneumonia in China, 2019. N Engl J Med. 2020;382(8):727-733. doi:10.1056/NEJMoa2001017

2. Xia J, Tong J, Liu M, Shen Y, Guo D. Evaluation of coronavirus in tears and conjunctival secretions of patients with SARS-CoV-2 infection. J Med Virol. 2020;92(6):589-594. doi:10.1002/jmv.25725
3. Rothan HA, Byrareddy SN. The epidemiology and pathogenesis of coronavirus disease (COVID-19) outbreak. J Autoimmun. 2020;109:102433. doi:10.1016/j.jaut.2020.102433

4. Cucinotta D, Vanelli M. WHO declares COVID-19 a pandemic. Acta Biomed. 2020;91(1):157-160.

5. Emanuel EJ, Persad G, Upshur R. Fair allocation of scarce medical resources in the time of covid-19. $N$ Engl J Med. 2020;382 (21):2049-2055. doi:10.1056/NEJMsb2005114

6. Lee Y, Kirubarajan A, Patro N, Soon MS, Doumouras AG, Hong D. Impact of hospital lockdown secondary to COVID-19 and past pandemics on surgical practice: a living rapid systematic review. $\mathrm{Am}$ J Surg. 2021;222(1):67-85.

7. Schwartz J, King CC, Yen MY. Protecting Healthcare Workers During the Coronavirus Disease 2019 (COVID-19) Outbreak: Lessons From Taiwan's Severe Acute Respiratory Syndrome Response. Clinical Infectious Diseases. 2020;71(15):858-860.

8. Truog RD, Mitchell C, Daley GQ. The toughest triage - allocating ventilators in a pandemic. $N$ Engl J Med. 2020;382(21):1973-1975. doi:10.1056/NEJMp2005689

9. Cheung N, Mitchell P, Wong TY. Diabetic retinopathy. Lancet. 2010;376(9735):124-136. doi:10.1016/S0140-6736(09)62124-3

10. Klein R, Klein BE, Moss SE. Visual impairment in diabetes. Ophthalmology. 1984;91:1-9. doi:10.1016/S0161-6420(84)34337-8

11. Klein BE. Overview of epidemiologic studies of diabetic retinopathy. Ophthalmic Epidemiol. 2007;14(4):179-183. doi:10.1080/ 09286580701396720

12. Al-Amer RM, Khader Y, Malas S, Abu-Yaghi N, Al-Bdour M, Ajlouni K. Prevalence and risk factors of diabetic retinopathy among Jordanian patients with type 2 diabetes. Digit J Ophthalmol. 2008;14:42-49. doi:10.5693/djo.01.2008.013

13. Teo ZL, Tham YC, Yu M, et al. Global prevalence of diabetic retinopathy and projection of burden through 2045: systematic review and meta-analysis. Ophthalmology. 2021. S0161-6420(21)00321-3. doi:10.1016/j.ophtha.2021.04.027

14. Tilahun M, Gobena T, Dereje D, Welde M, Yideg G. Prevalence of diabetic retinopathy and its associated factors among diabetic patients at Debre Markos referral hospital, Northwest Ethiopia, 2019: Hospital-Based Cross-Sectional Study. Diabetes Metab Syndr Obes. 2020;13:2179-2187. doi:10.2147/DMSO.S260694

15. Schulze-Bonsel K, Feltgen N, Burau H, Hansen L, Bach M. Visual acuities "hand motion" and "counting fingers" can be quantified with the freiburg visual acuity test. Invest Ophthalmol Vis Sci. 2006;47 (3):1236-1240. doi:10.1167/iovs.05-0981

16. American Academy of Ophthalmology Retina-Vitreous Panel. Preferred Practice Pattern ${ }^{\circledR}$ Guidelines. Diabetic Retinopathy. San Francisco, CA: (C) American Academy of Ophthalmology; 2019. Available from: www.aao.org/ppp. Accessed June 8, 2020.

17. Ashkenazy N, Goduni L, Smiddy WE. Short-term effects of COVID-19-related deferral of intravitreal injection visits. Clin Ophthalmol. 2021;15:413-417. doi:10.2147/OPTH.S296345

18. Elfalah M, AlRyalat SA, Toro MD, et al. Delayed intravitreal anti-VEGF therapy for patients during the COVID-19 lockdown: an ethical endeavor. Clin Ophthalmol. 2021;15:661-669. doi:10.2147/ OPTH.S289068

19. Ferris FLIII. How effective are treatments for diabetic retinopathy? JAMA. 1993;269:1290-1291. doi:10.1001/jama.1993.03500100088034

20. Gross JG, Glassman AR, Jampol LM, et al; Writing Committee for the Diabetic Retinopathy Clinical Research Network. Panretinal photocoagulation vs intravitreous ranibizumab for proliferative diabetic retinopathy: a randomized clinical trial. JAMA. 2015;314 (20):2137-2146. doi:10.1001/jama.2015.15217

21. Rajendram R, Fraser-Bell S, Kaines A, et al. A 2-year prospective randomized controlled trial of intravitreal bevacizumab or laser therapy (BOLT) in the management of diabetic macular edema: 24month data: report 3. Arch Ophthalmol. 2012;130:972-979. doi:10.1001/archophthalmol.2012.393 
22. Wells JA, Glassman AR, Ayala AR, et al; Diabetic Retinopathy Clinical Research Network. Aflibercept, bevacizumab, or ranibizumab for diabetic macular edema: two-year results from a comparative effectiveness randomized clinical trial. Ophthalmology. 2016;123 (6):1351-1359. doi:10.1016/j.ophtha.2016.02.022

23. The Diabetic Retinopathy Study Research Group, author. Photocoagulation treatment of proliferative diabetic retinopathy. Clinical application of Diabetic Retinopathy Study (DRS) findings, DRS report number 8. Ophthalmology. 1981;88:583-600.

24. Nentwich MM, Ulbig MW. Diabetic retinopathy - ocular complications of diabetes mellitus. World J Diabetes. 2015;6(3):489-499. doi:10.4239/wjd.v6.i3.489

25. Diabetic Retinopathy Vitrectomy Study Research Group. Early vitrectomy for severe proliferative diabetic retinopathy in eyes with useful vision. Results of a randomized trial. Diabetic Retinopathy Vitrectomy Study report 3. Ophthalmology. 1988;95:1307-1320. doi:10.1016/S0161-6420(88)33015-0

26. Aaberg TM. Pars plana vitrectomy for diabetic traction retinal detachment. Ophthalmology. 1981;88:639-642. doi:10.1016/S01616420(81)34973-2

27. Rice TA, Michels RG, Rice EF. Vitrectomy for diabetic traction retinal detachment involving the macula. Am J Ophthalmol. 1983;95:22-33. doi:10.1016/0002-9394(83)90330-6

28. Thompson JT, de Bustros S, Michels RG, Rice TA. Results and prognostic factors in vitrectomy for diabetic traction retinal detachment of the macula. Arch Ophthalmol. 1987;105:497-502. doi:10.1001/archopht.1987.01060040067035

29. El Annan J, Carvounis PE. Current management of vitreous hemorrhage due to proliferative diabetic retinopathy. Int Ophthalmol Clin. 2014;54(2):141-153. doi:10.1097/IIO.0000000000000027

30. Lu C-W, Liu X-F, Jia Z-F. 2019-nCoV transmission through the ocular surface must not be ignored. Lancet. 2020;395(10224):e39. doi:10.1016/S0140-6736(20)30313-5
31. Qing H, Li Z, Yang Z, et al. The possibility of COVID-19 transmission from eye to nose. Acta Ophthalmol. 2020;98(3):e388. doi:10.1111/aos.14412

32. Seah IY, Anderson DE, Kang AEZ, et al. Assessing viral shedding and infectivity of tears in coronavirus disease 2019 (COVID-19) patients. Ophthalmology. 2020;127(7):977. doi:10.1016/j. ophtha.2020.03.026

33. Wu P, Duan F, Luo C. Characteristics of ocular findings of patients with coronavirus disease 2019 (COVID-19) in Hubei Province, China. JAMA Ophthalmol. 2020;138(5):575-578.

34. Chen L, Liu M, Zhang Z, et al. Ocular manifestations of a hospitalised patient with confirmed 2019 novel coronavirus disease. $\mathrm{Br} J$ Ophthalmol. 2020;104(6):748-751.

35. Sungnak W, Huang N, Becavin C, et al. SARS-CoV-2 entry factors are highly expressed in nasal epithelial cells together with innate immune genes. Nat Med. 2020;26(5):681-687. doi:10.1038/s41591020-0868-6

36. Napoli PE, Nioi M, d'Aloja E, Fossarello M. The Ocular Surface and the Coronavirus Disease 2019: does a Dual 'Ocular Route' Exist? J Clin Med. 2020;9(5):1269. doi:10.3390/jcm9051269

37. Casagrande M, Fitzek A, Püschel K, et al. Detection of SARS-CoV-2 in human retinal biopsies of deceased COVID-19 patients. Ocul Immunol Inflamm. 2020;28(5):721-725. doi:10.1080/ 09273948.2020.1770301

38. Recommendations for urgent and nonurgent patient care [Internet]. Available from: https://www.aao.org/headline/new-recommenda tions-urgent-nonurgent-patient-care. Accessed June 19, 2020.

39. American Society of Retina Specialists (ASRS) member alert regarding the COVID-19 pandemic [Internet]. Available from: https://www. asrs.org/practice/asrs-member-alert-regarding-covid-19-pandemic. Accessed June 19, 2020.
Therapeutics and Clinical Risk Management

\section{Publish your work in this journal}

Therapeutics and Clinical Risk Management is an international, peerreviewed journal of clinical therapeutics and risk management, focusing on concise rapid reporting of clinical studies in all therapeutic areas, outcomes, safety, and programs for the effective, safe, and sustained use of medicines. This journal is indexed on PubMed Central, CAS,

\section{Dovepress}

EMBase, Scopus and the Elsevier Bibliographic databases. The manuscript management system is completely online and includes a very quick and fair peer-review system, which is all easy to use. Visit http://www.dovepress.com/testimonials.php to read real quotes from published authors. 